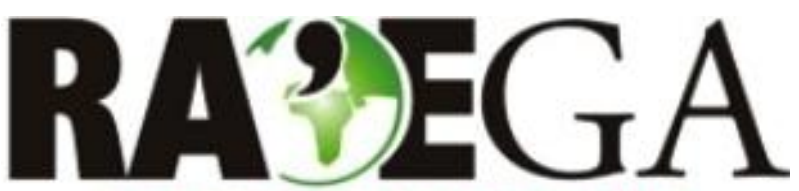

O ESPAÇO GEOGRÁFICO EM ANÁLISE

\title{
SISTEMA SÓCIO-ECOLÓGICO DA ILHA SÃO CRISTOVÃO, GALÁPAGOS: UMA ANÁLISE A PARTIR DAS PERCEPÇÕES DOS ATORES LOCAIS
}

\section{SOCIO-ECOLOGICAL SYSTEM OF SÃO CRISTOVÃO ISLAND, GALÁPAGOS: NA ANALYSIS OF THE PERCEPTIONS FROM LOCAL POPULATION}

\author{
Luis Vladimir Mora Andrade ${ }^{1}$, Gerciene de Jesus Miranda Lobato ${ }^{2}$, Peter Mann de Toledo ${ }^{3}$, Ima Célia \\ Guimarães Vieira $^{4}$
}

\begin{abstract}
RESUMO
Galápagos é um arquipélago considerado como um laboratório para o estudo da evolução, o primeiro Parque Nacional do Equador, e é Patrimônio Natural da Humanidade. Entretanto, com a chegada de cerca de 218 mil turistas ao ano, há pressão sobre os frágeis ecossistemas deste arquipélago insular. Esta pesquisa objetivou analisar o Sistema Sócioecológico (SSE) da Ilha São Cristovão a partir das percepções dos habitantes sobre ameaças, mudanças e impactos ocorridos a partir da publicação da Lei Especial de Galápagos em 10 de março de 1998 até 2017. As informações obtidas basearam-se em entrevistas semiestruturadas com 260 moradores, selecionados por amostragem probabilística do tipo aleatória simples. Ademais, aplicaram-se as técnicas exploratórias de análise fatorial de correspondência múltipla "AFCM" para 30 variáveis cuja descrição perpassa os problemas discutidos nas sessões da Organização das Nações Unidas para a Educação, a Ciência e a Cultura (UNESCO). A Ilha São Cristovão apresenta homens $(53,46 \%)$ e mulheres $(46,54 \%)$ residindo principalmente em Porto Baquerizo $(71,92 \%)$; a maioria (60\%) proveniente de outras ilhas povoadas (Santa Cruz, Florena e Isabela) e também do Equador continental. As correlações da análise estatística evidenciaram uma tendência a respostas positivas, contudo sinalizaram alguns impactos no modo de vida, especialmente relacionado ao aumento do turismo, às espécies introduzidas e à redução da mina, devido à extração de areia, cascalho e pedra para fazer as construções. Diante desse cenário, os atores locais delineiam um sistema com nuances sociais, ambientais e econômicas interligadas, mas conflitantes, necessitando de uma gestão mais eficaz.
\end{abstract}

Palavras chave: Conservação da biodiversidade; Sustentabilidade ambiental; Turismo; Equador

\section{ABSTRACT}

Galapagos is an archipelago of global interest considered as a laboratory for the study of evolution. As the first National Park created in Ecuador has been established as a Natural Heritage of Humanity. However, with the arrival of about 218 thousand tourists a year, there is constant pressure on the fragile ecosystems of these islands. This research aimed to analyze the Socio-Ecological System (SSE) of São Cristovão Island based on the inhabitants' perceptions of the threats, changes, and impacts that occurred as of the publication of the Special Law of Galapagos on March 10, 1998, until 2017. The information obtained was based on semi-structured interviews with 260 residents, selected by probabilistic sampling of the simple random type. Also, we applied the exploratory techniques of factorial analysis of multiple correspondences "AFCM" for 30 variables whose description per passes the problems discussed in the sessions of the United Nations Educational, Scientific and Cultural Organization (UNESCO). São Cristovão Island presents men (53.46\%) and women (46.54\%) residing mainly in Porto Baquerizo (71.92\%); the majority (60\%) coming from other populated islands (Santa Cruz, Florena and Isabela) and also from continental Ecuador. The correlations of the statistical analysis evidenced a tendency towards positive responses but indicated some impacts on the way of life, mainly related to the increase of the tourism, introduced species and the reduction of the mine, due to the extraction of sand, gravel, and stone to make the constructions. Given this scenario, local population outline a system with interrelated but conflicting social, environmental and economic nuances, requiring more effective management.

Keywords: Conservation of biodiversity; Environmental sustainability; Tourism; Ecuador.

\footnotetext{
${ }^{1}$ Universidade Federal do Pará, Belém/PA, email: vladimir197805@hotmail.com

2 Universidade Federal do Pará, Belém/PA, email:gercienelobato@hotmail.com

${ }^{3}$ Instituto Nacional de Pesquisas Espaciais, São José dos Campos/SP, email: peter.toledo@hotmail.com

${ }^{4}$ Museu Paraense Emílio Goeldi, Belém/PA, email: ima@museu-goeldi.br
} 


\section{SISTEMA SÓCIO-ECOLÓGICO DA ILHA SÃO CRISTÓVÃO, GALÁPAGOS: UMA ANÁLISE A PARTIR DAS PERCEPÇÕES DOS ATORES LOCAIS}

\section{INTRODUÇÃO}

O uso que as pessoas fazem da natureza é influenciado por fortes traços culturais onde estão embutidos valores, aspectos sociais e políticos, direito de uso, leis, governança e regras de mercado. Nesta dinâmica ocorre a integração dos processos e componentes socioeconômicos e biofísicos, formando um Sistema Sócioecológico (SSE) (BUSCHBACHER et al., 2016, p.21). Athayde et al. (2016, p.15) descrevem-no como um conjunto articulado entre atores sociais e suas instituições em escalas que vão desde a unidade dos recursos utilizados até os espaços ou territórios em que as comunidades encontram-se inseridas.

O uso que as pessoas fazem da natureza esta embutido no sistema socioeconômico (seus valores, relações sociais e politicas, direito de uso, leis, governança, mercado, entre outros) (BUSCHBACHER, 2014, p.13). Nas interações homem e ambiente um aspecto importante é a capacidade dos ecossistemas de fornecer bens e serviços para alcançar a sustentabilidade, por exemplo, os parques nacionais oferecem boas oportunidades para adquirir experiências do ambiente natural e os serviços ambientais que prevê (GROOT, 1992, p.322), ou seja, a conquista do desenvolvimento do milênio depende dos servicos proporcionados pelo sistema natural.

Segundo Tapia et al. (2009, p.129), em Galápagos os distintos componentes do SSE guardam estreitos vínculos entre si e estão interconectados por fluxos biofísicos, econômicos e socioculturais que operam em distintas escalas espaço temporais. Um dos pontos relevantes para a compreensão dos processos socioeconômicos e a mensuração dos impactos em Galápagos está no contexto da formação geológica do arquipélago e peculiaridade de sua biodiversidade (SANTOS et al., 2015, p.255).

As ilhas tropicais surgiram por processos tectônicos de forma isolada e não conectadas à história geológica do continente (THEOFILOS,
2011, p.144). Para o referido autor, esse isolamento no tempo, desde sua formação há cinco milhões de anos, permitiu que processos evolutivos produzissem uma biodiversidade de aspecto singular.

Os padrões biogeográficos nas ilhas são caracterizados por feições adaptativas únicas em condições ambientais extremas quanto a regimes climáticos e disponibilidade de água não salobra. Esta dinâmica adaptativa culminou na formação de uma comunidade de espécies endêmicas de animais configurados por várias radiações adaptativas (WALLACE, 2003, p. 536; GRANT; GRANT, 2008, p.02; BASSETT, 2009, p.30-31). Desta forma, Galápagos se tornou um dos principais pontos de grande interesse científico sobre processos evolutivos, e os padrões fenotípicos de algumas espécies de vertebrados chegou a inspirar o naturalista Charles Darwin em partes de suas hipóteses sobre a teoria da evolução.

Em 12 de Fevereiro de 1832, o governo do Equador tomou posse das Ilhas Galápagos, estabelecendo uma pequena colônia de pessoas na Ilha Floreana (LARSON, 2002, p 59.), um ano depois começou o primeiro projeto de colonização, onde um grupo de habitantes prisioneiros chegaram ao Equador para cumprir sua sentença (IDROVO, 2005, p.40 ). Em 1936, durante a presidência de Federico Páez, a província de Galápagos foi declarada Reserva Nacional de Fauna e Flora, medida que possibilitou a proteção da biodiversidade, com exceção de áreas povoadas. Em 20 de julho de 1959, mais de $96,7 \%$ do território foi declarado Parque Nacional de Galápagos (7800 km) e 3,3\% permaneceram do lado de fora (NICHOLLS, 2014, p.120). Em 23 de julho do mesmo ano, a Fundação Charles Darwin foi criada para as Ilhas Galápagos, a qual se dedicava a pesquisas sobre espécies da flora e fauna que deveriam ser protegidas e espécies estrangeiras que deveriam ser colonizadas (IDROVO, 2005, p.197). 


\section{SISTEMA SÓCIO-ECOLÓGICO DA ILHA SÃO CRISTÓVÃO, GALÁPAGOS: UMA ANÁLISE A PARTIR DAS PERCEPÇÕES DOS ATORES LOCAIS}

A área terrestre de Galápagos entrou para a Lista de Patrimônio Natural em 1978, fato justificado pela presença de novas espécies endêmicas bem como um número significativo de plantas e animais raros ou em perigo, requerendo um esforço para conservação. Em 1986, o governo do Equador criou a Reserva de Recursos Marinhos que atingiu 15 milhas náuticas, para completar o nível de proteção da flora e fauna nas ilhas (ECHEVERRIA, 2011, p.34) e em 1998, através da Lei Especial de Conservação e Desenvolvimento Sustentável da Província de Galápagos foi prevista uma extensão de 40 milhas, o equivalente a uma área de $130.000 \mathrm{~km}^{2}$, tornando-se a sétima maior reserva marinha do mundo, sendo permitida nessa reserva, apenas atividades como a pesca artesanal e o turismo de natureza (ECHEVERRIA, 2011. p.34; NICHOLLS, 2014 p.137).

A estruturação e organização formal do turismo nas ilhas Galápagos com interesse de conhecer o santuário ecológico iniciou apenas em 1969. Contudo, a gestão do território tem sido complexa e dinâmica, caracterizada por diversas mudanças ao longo dos últimos 30 anos, conforme indicado no plano de gestão oficial (DPNG, 2005, p.10; 2014, p.48), e promotora de mudanças de organização e controle no arquipélago.

Galápagos é frequentemente citada quando se trata de conflitos relacionados entre a conservação de recursos e o desenvolvimento econômico, associado também às pressões do turismo na natureza, particularmente sobre espécies emblemáticas, paisagens únicas $\mathrm{e}$ ambientes marinhos, os quais se desenvolveram e evoluíram como consequência do isolamento geográfico e ecológico que gerou disponibilidade de nichos para colonização. Modelos dinâmicos, usadas para examinar as interações entre o homem e o ambiente nas Ilhas Galápagos e as políticas, descrevem efeitos geradores de diferentes respostas humanas e alguns desses resultados são prejudiciais para a sustentabilidade sócioecológica em Galápagos (WALSH; MENA, 2016, p.14536).

Neste contexto, os problemas apresentados no arquipélago têm sido analisados e discutidos nas sessões da UNESCO no período 1998 até 2016, sendo esta uma estratégia do governo equatoriano para expor avanços significativos sobre a gestão do território. Assim, compreendendo Galápagos como um Sistema Sócioecológico, esta pesquisa objetivou analisar a Ilha de São Cristóvão a partir das percepções dos habitantes sobre ameaças, mudanças e impactos ocorridos a partir da publicação da Lei Especial de Galápagos em 10 de março de 1998 até 2017.

\section{MATERIAIS E MÉTODOS}

\section{1 Área de estudo}

O arquipélago de Galápagos é isolado do continente americano a uma distância aproximada de $960 \mathrm{~km}$ do Equador (Figura 1), sendo localizado a $928 \mathrm{~km}$ da ilha dos Cocos, na Costa Rica, e a 3700 km da ilha de Juan Fernández, no Chile (BARRIGA, 2015, p.405). O arquipélago é composto por 13 ilhas com mais de $10 \mathrm{~km}^{2}$ de superfície, cinco ilhas médias entre um a cinco $\mathrm{km}^{2}$ de superfície e as restantes 216 unidades são ilhotas e rochas atingindo um total de 234 unidades terrestres, sendo este um número variável porque está sujeito a atualização, pois como são de origem vulcânica pode originar outras ilhas (DPNG, 2005, p.18; 2014 p.26). 


\section{SISTEMA SÓCIO-ECOLÓGICO DA ILHA SÃO CRISTÓVÃO, GALÁPAGOS: UMA ANÁLISE A PARTIR DAS PERCEPÇÕES DOS ATORES LOCAIS}

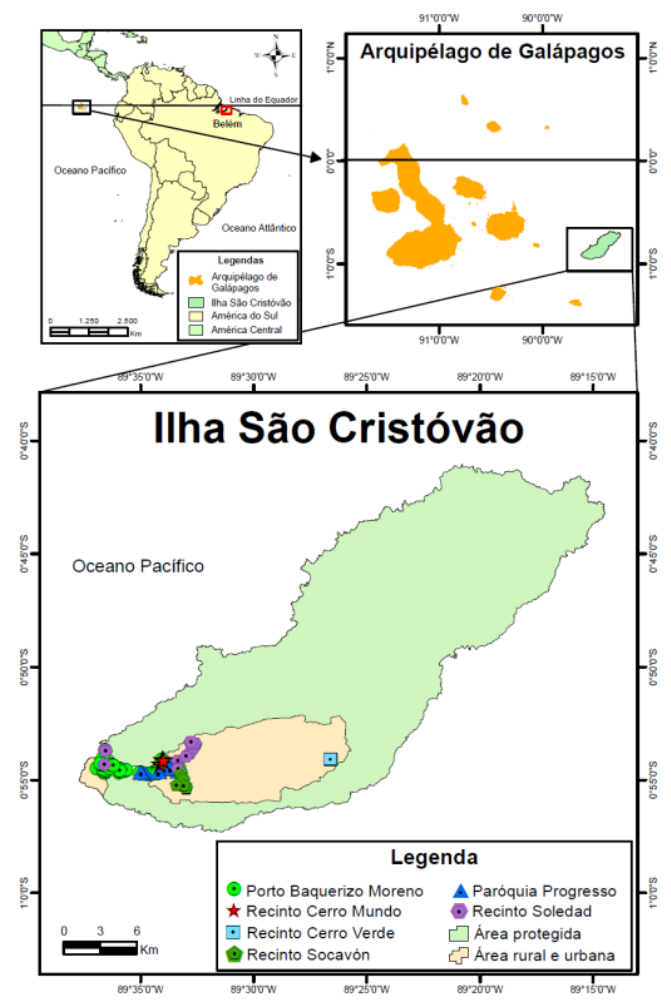

Figura 1 - Localização do Arquipélago de Galápagos, Equador.

Outro ponto importante é a Reserva Marinha de Galápagos criada em 1998 com a emissão da Lei Especial de Galápagos, e compreende uma faixa de 40 milhas com uma área de $138.000 \mathrm{~km}^{2}$, tornando-se a sétima maior área protegida marinha do mundo (GALAPAGOS, 1998, p.08). O Arquipélago foi declarado província do Equador em 18 de fevereiro de 1973, porque o governou reconheceu seu valor biológico e como ponto turístico. Conforme o Plano de Gestão de 2014 (DPNG, 2014, p.29), Galápagos está dividido politicamente em três territórios: Ilha de São Cristóvão com seu capital Porto Baquerizo Moreno (Figura 1), onde estão situadas as instituições governamentais; Ilha de Santa Cruz com sua cidade Porto Ayora onde está a maior infraestrutura hoteleira e Ilha Isabela com sua cidade pequena Porto Villamil, que depende da pesca e do turismo que Porto Ayora oferece.

\subsection{Contexto estudado}

A Ilha de São Cristovão (Figura 1) foi selecionada para este estudo, uma vez que questões centrais sobre a gestão e normatização no arquipélago são discutidas nesta localidade. A declaração como província desta ilha, favoreceu a implementação de um gabinete do governo, projetos públicos, hospitais e estradas, bem como aumentou o turismo e gerou imigração entre as ilhas do arquipélago (IDROVO, 2005 p. 214), tornando assim, um ambiente oportuno para investigar as percepções dos moradores sobre as políticas das instituições locais, e as recomendações da UNESCO que buscam preservar este patrimônio.

Foram realizadas entrevistas semiestruturadas (Figuras 2A e B), baseadas em Sobreiro (2016, p.120), com residentes de Porto Barquerizo Moreno e o bairro rural de Progresso com suas vilas de Soledade, Socavón, Cerro mundo e Cerro verde. Para tanto, foi utilizado questionário com 46 perguntas que versavam sobre: a) Caracterização social, b) Ambiente, c) Turismo, d) Educação, e) Pesca, f) Espécies introduzidas e g) Aspectos Institucionais. 


\section{SISTEMA SÓCIO-ECOLÓGICO DA ILHA SÃO CRISTÓVÃO, GALÁPAGOS: UMA ANÁLISE A PARTIR DAS PERCEPÇÕES DOS ATORES LOCAIS}

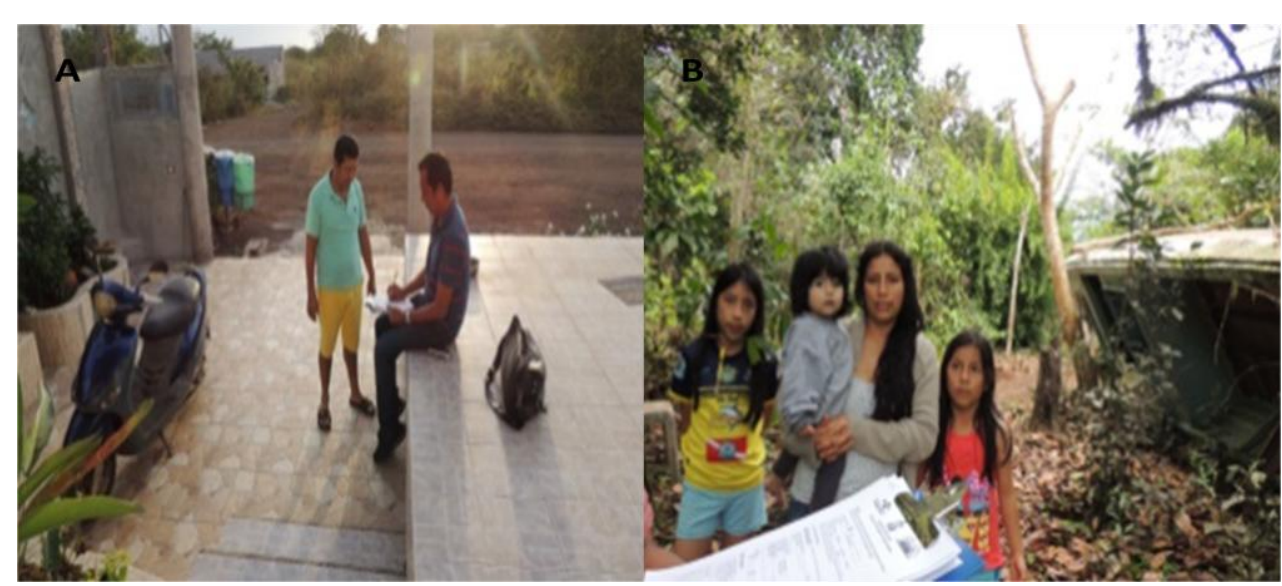

Figura 2. Entrevistas. A. Residência localizada em Porto Baquerizo Moreno, Ilha São Cristóvão, Galápagos; B. Área rural em Recinto Socavón.

Para realizar a projeção do tamanho da amostra usada na análise, foi necessário conhecer o número de residentes em Porto Baquerizo Moreno. Segundo informações disponíveis no sitio eletrônico da Secretaria Nacional de Planejamento (2016) o tamanho da população no ano em 2017 para a cidade de Porto Baquerizo Moreno e bairro Progresso e seus recintos foi estimado em 8.909 residentes. Considerando estes dados, calculou-se o tamanho da amostra de entrevistados, para população finita, com um nível de confiança de $90 \%, Z=1,645$, com a margem de erro de $5 \%$, conforme mostrada abaixo:

$$
n=\frac{N \cdot Z^{2} \cdot p \cdot(1-p)}{(N-1) \cdot e^{2}+Z^{2} \cdot p \cdot(1-p)}
$$

$\mathbf{n}=$ Tamanho da amostra que se quer calcular

$\mathbf{N}=$ Tamanho do universo

$\mathbf{Z}=$ É o desvio do valor médio que se aceita para alcançar o nível de confiança desejado, os valores mais

- $\quad$ Nível de confiança $90 \% Z=1,645$

- Nível de confiança $95 \% Z=1,96$

$\mathbf{E}=\mathrm{A}$ margem de erro máximo que se quer admitir (5\%)

$\mathbf{P}=$ Como regra geral $\mathrm{p}=50 \%$

Com base nessas informações, o tamanho da amostra do presente estudo foi correspondente a 260 pessoas. As entrevistas com questionários foram dirigidas às populações da área urbana (Porto Baquerizo Moreno) e rural (Recintos Progreso, Cerro Verde, Soledad, Socavon e Cerro Mundo), no período de dois meses (05 de junho a 05 de agosto de 2017). Os entrevistados foram escolhidos de maneira aleatória, contudo deveriam obedecer aos seguintes critérios: maiores de 18 anos de idade, pai ou mãe, possuírem tempo de residência na Ilha São Cristóvão maior que um ano.

Para as informações obtidas foram realizadas abordagem qualitativa, para compreender as respostas dos moradores aos questionamentos; e quantitativa com aplicação das técnicas exploratórias de análise fatorial múltipla e análise de Cluster - tree clustering e $k$ means of clustering de correspondência através do uso da estatística multivariada, com o programa Statistica 6.0 da Statsoft. O programa Statistica também foi utilizado para fazer a análise fatorial de correspondência múltipla "AFCM".

As 46 perguntas encontram-se agrupadas em 30 variáveis, que foram, seguindo a metodologia de Scatena (2005, p. 62), codificadas com zero (0) quando se referiu a "Não" e um (1) quando se referiu a "Sim" (Quadro um), para ser usada como entrada de dados brutos desta análise. 
ANDRADE, L. V. M., LOBATO, G. J. M. , TOLEDO, P. M. , VIERIA, I. C. G.

\section{SISTEMA SÓCIO-ECOLÓGICO DA ILHA SÃO CRISTÓVÃO, GALÁPAGOS: UMA ANÁLISE A PARTIR DAS PERCEPÇÕES DOS ATORES LOCAIS}

Quadro 1 - Variáveis e codificações utilizadas na análise estatística.

\begin{tabular}{|c|}
\hline Variáveis e suas codificações \\
\hline $\begin{array}{l}\text { A1:0 Não é um turismo de conservação da flora e fauna } \\
\text { A1:1 É um turismo de conservação da flora e fauna }\end{array}$ \\
\hline A2:0 O turismo não é economicamente bom para as grandes empresas \\
\hline A2:1 0 turismo é economicamente bom para as grandes empresas \\
\hline A3:0 Turismo não é uma ameaça para conservação da ilha São Cristóvão \\
\hline A3:1 Turismo é uma amaça para conservação da ilha São Cristóvão \\
\hline A4:0 Parque Nacional não faz os controles nos sítios de visitas \\
\hline A4:1 Parque Nacional faz os controles nos sítios de visitas \\
\hline A5:0 Não tem aumentado a população devido a migração e natalidade \\
\hline A5:1 Tem aumentado a população devido migração e natalidade \\
\hline A6:0 Não tem melhorado a administração do sistema de resíduos sólidos \\
\hline A6:1 Tem melhorado a administração do sistema de resíduos sólidos \\
\hline A7:0 Não existe um sistema efetivo de manejo de águas residuais \\
\hline A7:1 Existe um sistema efetivo de manejo de águas residuais \\
\hline A8:0 Não existe um sistema efetivo de manejo de resíduos sólidos \\
\hline A8:1 Existe um sistema efetivo de manejo de resíduos sólidos \\
\hline A9:0 Não conhece o que é viver em um Patrimônio Natural da Humanidade \\
\hline A9:1 Conhece o que é viver em um Patrimônio Natural da Humanidade \\
\hline A10:0 Não é um privilégio viver em um Patrimônio \\
\hline A10:1 É um privilégio viver em um Patrimônio \\
\hline A11:0 Não tem pesca em época de piracema \\
\hline A11:1Tem pesca em época de piracema \\
\hline A12:0 Não é uma ameaça a pesca ilegal por barcos nacionais e estrangeiros \\
\hline A12:1 É uma ameaça a pesca ilegal por barcos nacionais e estrangeiros \\
\hline A13:0 Não conhecia que pepino do mar está ameaçado e é proibido pescar \\
\hline A13:1 Conhecia que o pepino do mar está ameaçado e é proibido pescar \\
\hline A14:0 A sobrepesca não causa diminuição do pepino do mar \\
\hline A14:1 A sobrepesca causa a diminuição do pepino do mar \\
\hline A15:0 As espécies introduzidas não são uma ameaça para as espécies endêmicas \\
\hline A15:1 As espécies introduzidas são uma ameaça para as espécies endêmicas \\
\hline A16:0 Não conhece as medidas de biossegurança existentes \\
\hline A16:1 Conhece as medidas de biossegurança existentes \\
\hline A17:0 Não é uma medida de controle de biossegurança mais apropriada informar \\
\hline A17:1 É uma medida de controle de biossegurança mais apropriada informar \\
\hline $\begin{array}{l}\text { A18:0 Aumento de chegadas de voos domésticos a ilha São Cristóvão não aumenta o risco } \\
\text { de ingresso de espécies introduzidas }\end{array}$ \\
\hline $\begin{array}{l}\text { A18:1 Aumento de chegadas de voos domésticos a ilha São Cristóvão aumenta o risco de } \\
\text { ingresso de espécies introduzidas }\end{array}$ \\
\hline $\begin{array}{l}\text { A19:0 Aumento de chegadas de embarcações de carga a ilha São Cristóvão não aumenta } \\
\text { o risco de ingresso de espécies introduzidas }\end{array}$ \\
\hline $\begin{array}{l}\text { A19:1 Aumento de chegadas de embarcações de carga a ilha São Cristóvão aumenta o } \\
\text { risco de ingresso de espécies introduzidas }\end{array}$ \\
\hline A20:0 O sistema de biossegurança não está funcionando corretamente \\
\hline A20:1 O sistema de biossegurança está funcionando corretamen \\
\hline
\end{tabular}


ANDRADE, L. V. M., LOBATO, G. J. M. , TOLEDO, P. M. , VIERIA, I. C. G.

\section{SISTEMA SÓCIO-ECOLÓGICO DA ILHA SÃO CRISTÓVÃO, GALÁPAGOS: UMA ANÁLISE A PARTIR DAS PERCEPÇÕES DOS ATORES LOCAIS}

\begin{tabular}{l} 
A21:0 A implementação de um porto na ilha de Baltra e outro em Guayaquil como únicos \\
pontos autorizados no embarque e desembarque de carga não melhoraria os controles \\
A21:1 A implementação de um portona ilha de Baltra e outro em Guayaquil como único \\
pontos autorizados no embarque e desembarque de carga melhoraria os controles \\
A22:0 A estratégia para optar por um cargo público não é ter formação em pós graduação \\
e idiomas \\
A22:1 A estratégia para optar por um cargo público é ter formação em pós graduação e \\
idiomas \\
A23:0 Os residentes não conhecem a Lei Especial de Galápagos \\
A23:1 Os residentes conhecem a Lei Especial de Galápagos \\
A24:0 A lei especial de Galápagos não é importante para a conservação \\
A24:1 A lei especial de Galápagos é importante para a conservação \\
\hline A25:0 A gestão do Parque Nacional não contribui para conservação de biodiversidade \\
A25:1 A gestão do Parque Nacional contribui para conservação de biodiversidade \\
A26:0 Não está de acordo com o zoneamento como uma ferramenta de organização de \\
atividades na ilha São Cristóvão \\
A26:1 Está de acordo com zoneamento como uma ferramenta de organização de \\
atividades na ilha São Cristóvão \\
\hline A27:0 Não existe conflito entre a gestão do Parque Nacional e os habitantes \\
A27:1 Existe conflito entre a gestão do Parque Nacional e os habitantes \\
\hline A28:0 Não é possível alcançar uma agricultura local sustentável de baixo impacto na ilha \\
São Cristóvão \\
A28:1 É possível alcançar uma agricultura local sustentável de baixo impacto na ilha São \\
Cristóvão \\
A29:0 Não é ameaça a expansão e desenvolvimento de espécies introduzidas de flora e \\
fauna na ilha São Cristóvão \\
A29:1 É ameaça a expansão e desenvolvimento de espécies introduzidas de flora e fauna \\
na ilha São Cristóvão \\
A30:0 A mina que está próximo a praia Loberia não está reduzindo a nível crítico pela \\
extração de areia, cascalho e pedra para fazer as construções \\
A30:1 A mina que está próximo a praia Loberia esta reduzindo a nível crítico pela extração \\
de areia, cascalho e pedra para fazer as construções \\
\hline
\end{tabular}

As variáveis perpassam os problemas levantados pela UNESCO (1. Turismo, 2. Espécieis introduzidas, 3. Falta de um sistema efetivo de gerenciamento de resíduos sólidos e manejo de águas residuais, 4. Ausência de ordenamento institucional). Aliado a isso, considerou também como dificuldades: 5. A pesca e 6. 0 reconhecimento de Galápagos como Patrimônio de Valor Universal. Desta forma, as 30 variáveis percorrem estes seis aspectos, considerados nesse estudo como condutores de mudança no SSE.

\section{RESULTADOS E DISCUSSÃO}

\subsection{Perfil socioeconômico da llha São Cristovão}

$\mathrm{Na}$ ocasião da pesquisa foram entrevistados 260 residentes. $\mathrm{Na}$ tabela 1 apresenta-se um panorama geral de suas condições socioeconômicas. 
ANDRADE, L. V. M., LOBATO, G. J. M. , TOLEDO, P. M. , VIERIA, I. C. G.

\section{SISTEMA SÓCIO-ECOLÓGICO DA ILHA SÃO CRISTÓVÃO, GALÁPAGOS: UMA ANÁLISE A PARTIR DAS PERCEPÇÕES DOS ATORES LOCAIS}

Tabela 1 - Condições socioeconômicas dos residentes da Ilha São Cristovão, Galápagos.

\begin{tabular}{|c|c|c|}
\hline Variável & Classificação & Percetual (\%) \\
\hline \multirow{2}{*}{ Sexo } & Masculino & $53,46 \%$ \\
\hline & Feminino & $46,54 \%$ \\
\hline \multirow{6}{*}{$\begin{array}{l}\text { Local de Moradia dos } \\
\text { Entrevistados }\end{array}$} & Porto Baquerizo & $71,92 \%$ \\
\hline & Recinto Progresso & $11,92 \%$ \\
\hline & Recinto Soledade & $6,54 \%$ \\
\hline & Recinto Cerro Verde & $3,08 \%$ \\
\hline & Recinto Socavón & $5 \%$ \\
\hline & Recinto Cerro Mundo & $1,54 \%$ \\
\hline \multirow{3}{*}{ Origem } & Galápagos & $60 \%$ \\
\hline & Guayas & $10,77 \%$ \\
\hline & Outro & $29,23 \%$ \\
\hline \multirow{7}{*}{ Faixa etária } & 19 a 25 anos & $9,23 \%$ \\
\hline & 26 a 32 anos & $20,77 \%$ \\
\hline & 33 a 39 anos & $14,62 \%$ \\
\hline & 40 a 46 anos & $14,23 \%$ \\
\hline & 47 a 53 anos & $15,77 \%$ \\
\hline & 54 a 60 anos & $12,69 \%$ \\
\hline & Acima de 60 anos & $12,69 \%$ \\
\hline \multirow{4}{*}{ Estado Civil } & Casado & $57,31 \%$ \\
\hline & Solteiro & $24,62 \%$ \\
\hline & União Livre & $13,08 \%$ \\
\hline & Outro & $5 \%$ \\
\hline \multirow{3}{*}{ Educação } & Superior completo & $41,15 \%$ \\
\hline & Ensino médio completo & $34,62 \%$ \\
\hline & Ensino fundamental completo & $12,69 \%$ \\
\hline \multirow{3}{*}{ Ocupação } & Funcionários públicos & $31,92 \%$ \\
\hline & Pessoas que se dedicam ao turismo & $22,69 \%$ \\
\hline & Donas de casa & $11,54 \%$ \\
\hline
\end{tabular}

Com base nesse perfil, vale especificar alguns pontos importantes. $\mathrm{Na}$ questão educacional, 58,85\% não apresentaram uma profissão reconhecida por um diploma universitário, contudo $8 \%$ são biólogos marinhos, $6,92 \%$ são bacharéis em educação, profissionais estes que atuam em escolas de nível médio. As profissões mais representativas são aquelas relacionadas a instituições públicas e empresas privadas dedicadas ao turismo, por exemplo, $21 \%$ dos entrevistados são biólogos marinhos, seguidos por 18\% graduados em educação, seguidos por administradores e graduados em turismo com $12 \%$ e $10 \%$ dos entrevistados, respectivamente.

A respeito da origem, registrou-se que $60 \%$ são chamados de residentes permanentes, ou seja, são pessoas que chegaram na ilha por volta do ano de 1985 a 1998 e criaram laços familiares e empregatícios, sendo que 


\section{SISTEMA SÓCIO-ECOLÓGICO DA ILHA SÃO CRISTÓVÃO, GALÁPAGOS: UMA ANÁLISE A PARTIR DAS PERCEPÇÕES DOS ATORES LOCAIS}

aproximadamente $30 \%$ dos moradores vivem na região a cerca de 16 a 29 anos. Galápagos não tem população nativa. Os processos de colonização iniciaram em 1832 com a posse do território pelo governo equatoriano, favorecendo a migração para a ilha. Em 1998 foi publicada a Lei Especial de Galápagos que estabeleceu limite de mobilidade e comércio com o Equador continental, mecanismo este que reduziu a entrada de migrantes. As pessoas vieram para Galápagos motivadas pelo trabalho (53,46\%); porque as famílias vivem em São Cristóvão $(28,46 \%)$; ou ainda porque gostam do clima da ilha (14,23\%).

Além destas variáveis mostradas na tabela 1 , houve relatos dos moradores sobre a paisagem, locais turísticos, migração e dificuldades que encontram na vida cotidiana. Para a paisagem, $70 \%$ dos moradores narraram que gostam do lugar, especialmente pela tranqüilidade e pela natureza, e a biodiversidade $(24,23 \%)$. No entanto, 35\% relataram que houve impacto na paisagem pela extração de pedra para a construção de casas, rodovias e projetos governamentais, haja vista que não tem outro espaço, uma vez que são áreas protegidas.
Entre os locais turísticos (Figura 3) mais atrativos pela beleza cênica, $25,77 \%$ citaram a Lagoa de Junco (Figura 4A), a qual é a única de água doce em Galápagos. Reconhecida mundialmente por sua biodiversidade de flora e fauna endêmicas, 86,15\% respondentes sugerem que não há nada a mudar na paisagem da ilha São Cristovão, pois tem orgulho do seu ambiente natural. No entanto, $10 \%$ sugeriram que deveria voltar para o que era há 30 anos, onde existiam poucas casas e poucas pessoas.

A praia dos Marinheiros (Figura 4B) era usada para o lazer de crianças, mas $23,85 \%$ dos entrevistados disseram que essa praia passou a ser um local de manutenção de barco. A esse respeito, $10,38 \%$ descreveram que o Pedreal (Figura 4C), porto de águas profundas e lugar onde as pessoas aproveitam o mar, tornou-se um local de desembarque e embarques de contêineres provenientes do continente equatoriano. Praias de Porto Chino, Praia Mann, Colina do Bruxo (Figura 4D, 4E e 4F, respectivamente), indicadas por $7,69 \%$ dos entrevistados, são locais turísticos, porém têm bastante lixo como plásticos e outros poluentes.

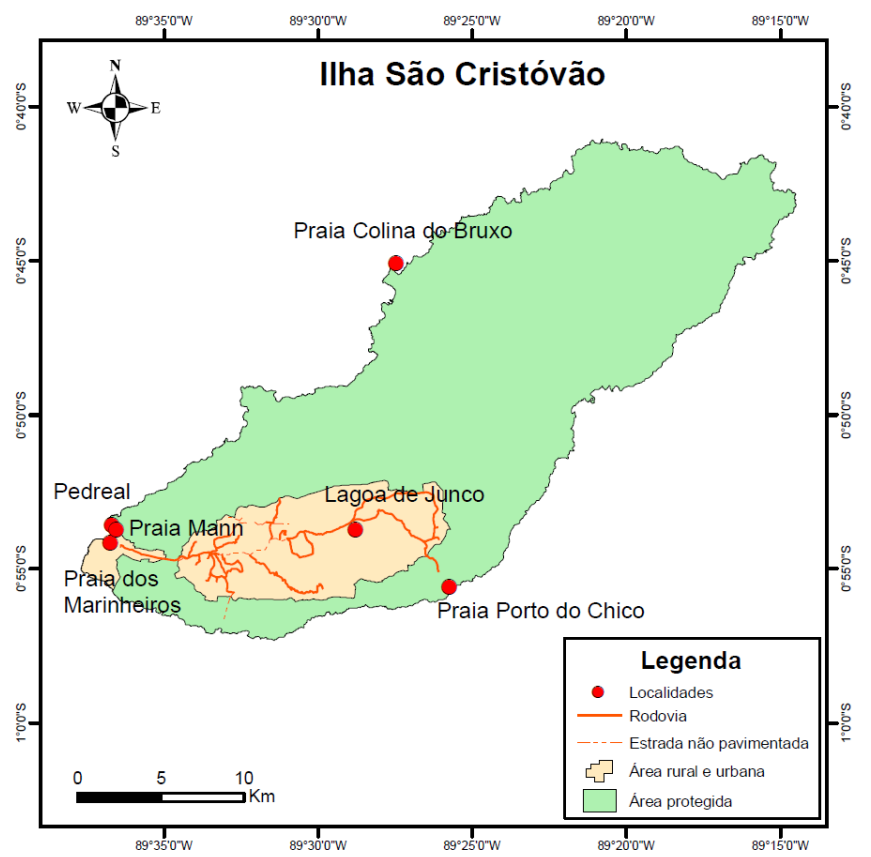

Figura 3 - Mapa de Localização da Lagoa de Junco, Praia dos Marinheiros, Pedreal, Praias de Porto Chino, Praia Mann, Colina do Bruxo, Ilha de São Cristóvão, Galápagos. 


\section{SISTEMA SÓCIO-ECOLÓGICO DA ILHA SÃO CRISTÓVÃO, GALÁPAGOS: UMA ANÁLISE A PARTIR DAS PERCEPÇÕES DOS ATORES LOCAIS}

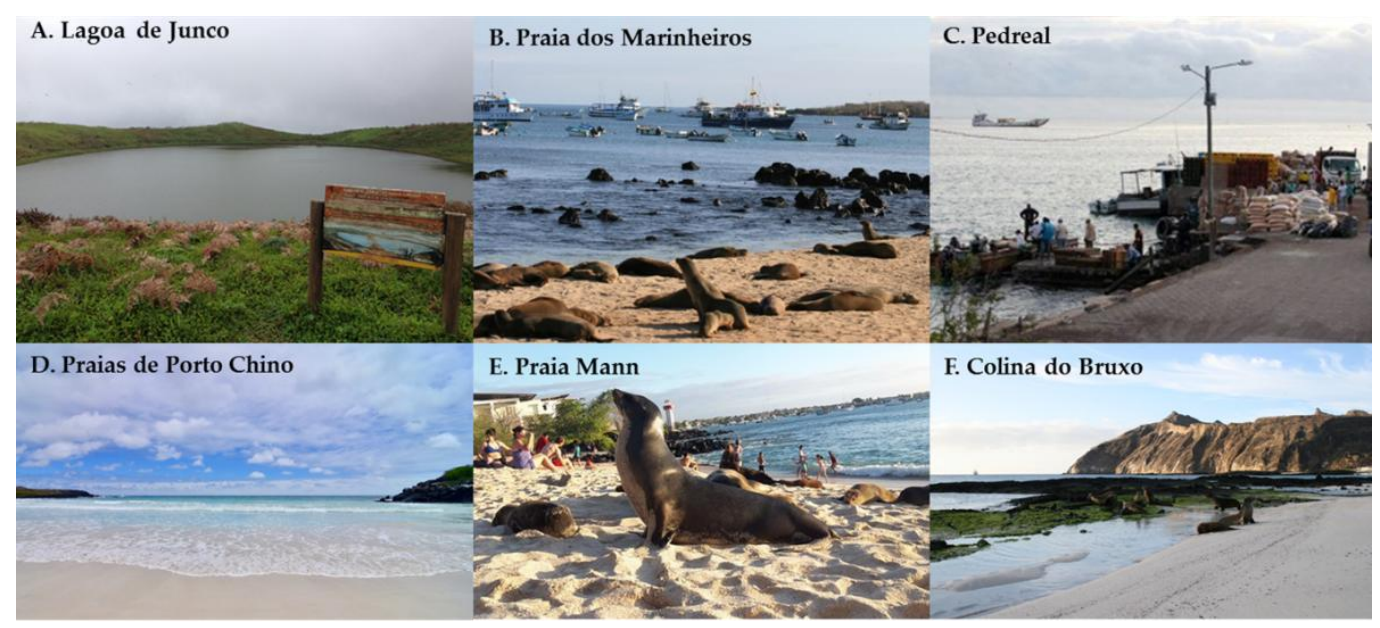

Figura 4 - A. Lagoa de Junco; B. Praia dos Marinheiros; C. Pedreal; D. Praias de Porto Chino; E.

Praia Mann; F. Colina do Bruxo, Ilha de São Cristóvão, Galápagos. Fonte: Pesquisa de campo (2017).

$\mathrm{O}$ agente promotor da economia da ilha é o turismo, que originou a necessidade de contratar homens e mulheres do Equador Continental e que, por sua vez, gerou imigração para Galápagos (WALSH; MENA, 2016, p.14537). Conforme discutem estes autores, a população permanente é pequena (aproximadamente 30.000), mas crescente e dinâmica. Não há população indígena, e no primeiro censo de 1972, 3.488 residentes e, em 1990, 10.000 moradores foram contados. O turismo está crescendo exponencialmente. Em 2015, havia 25225.000 turistas que visitaram Galápagos, em comparação com 65.000 em 2000 e 40.000 em 1990. Neste tema, de acordo com $58,85 \%$ dos entrevistados, o crescimento populacional é devido à imigração e natalidade. Com a Lei Especial promulgada em 1998, Galápagos foi declarada de regime especial e, para sua conservação, é limitada a livre mobilidade e o comércio. Contudo, 32,69\% dos entrevistados consideram que ganhar $80 \%$ mais do que no Equador Continental motiva o trânsito humano. Finalmente, a Lei Especial de Galápagos promulga dar preferência de trabalho aos residentes, no entanto, 4,21\% dos entrevistados sugerem que este não é o caso.

Diante desse quadro geral da Ilha São Cristovão fica perceptível um sistema complexo com nuances social, ecológico e econômico interligadas, mas conflitantes. Para Tapia et al.
(2009, p.133), a dinâmica do sistema social é sustentada em vários processos culturais, sociopolíticos e econômicos, mediados por uma série de atores que interagem de forma complexa uns com os outros e com o sistema natural. Essas interações são comandadas por lógicas de relacionamento parcialmente independentes dos padrões de funcionamento do ecossistema, como o equilíbrio de poder entre os atores, a interação entre seus interesses materiais e os patrimônios culturais em que se movem.

A ciência e a conservação em Galápagos se tornam mais complexas com o aumento do número de organizações. Para 2006, foram 16 instituições não governamentais com presença física em Galápagos, e pelo menos 60 fundações nacionais e internacionais que fornecem assistência financeira à Galápagos, mas não têm presença física no arquipélago (WATKINGS; MARTINEZ, 2007, p.19). A declaração da UNESCO em 2007 (p.09) aponta que Galápagos sofre "uma abordagem fragmentária de planejamento, falta de coordenação interinstitucional, falta de vontade política, liderança e autoridade", e que, portanto, "há um enfraquecimento das instituições". Resultante dessa situação houve a publicação da nova Constituição da República do Equador, que através do artigo 258 permitiu a fusão entre Instituto Nacional de Galápagos (INGALA) e do governo provincial em uma 


\section{SISTEMA SÓCIO-ECOLÓGICO DA ILHA SÃO CRISTÓVÃO, GALÁPAGOS: UMA ANÁLISE A PARTIR DAS PERCEPÇÕES DOS ATORES LOCAIS}

organização chamada Conselho do Regime Especial de Galápagos "LOREG", como um esforço para simplificar a governança nas ilhas (CAIRNS, 2011, p.22).

Condutores de mudanças: o que os atores sociais pensam sobre o SSE da Ilha São Cristovão?

\subsection{Turismo}

As Ilhas Galápagos são um conjunto de maravilhas da natureza, encantando tanto os residentes permanentes como os turistas (PALOMO et al., 2014, p.186). Essa interpretação corresponde ao trabalho realizado na llha São Cristóvão, onde $24,2 \%$ concordam que é um dever de todos conservarem a flora e a fauna do arquipélago. $\mathrm{O}$ desejo dos residentes é que os turistas visitem tudo o que há na ilha; $15 \%$ dos entrevistados acreditam que os proprietários de restaurantes e hotéis têm cuidado para oferecer serviços de qualidade bem como há guias turísticos para completar a estadia; 14,2\% acreditam que deve haver mais turistas para ficar, porque às vezes só são vistos quando eles levam seu barco para viajar pelas ilhas ou quando eles vão para o aeroporto de volta ao continente equatoriano. Para Walsh e Mena (2016, p.14537) essas viagens tornaram-se regra desde 2009, quando o turismo de cruzeiro navegável diminuiu devido à recessão econômica.

São Cristóvão é a capital da província de Galápagos, a qual tem um aeroporto em que o turista chega das cidades de Quito e Guayaquil; portanto, oferece alguns lugares para conhecer e observar a flora e a fauna e explorar suas paisagens. A esse respeito, $13,5 \%$ dos entrevistados concordaram que a desvantagem gerada pela falta de informação, promoção e disseminação da Ilha São Cristóvão se deve ao fato de que a maioria das tarifas aéreas e pacotes turísticos oferecidos pelas agências de viagens são vendidos em maior demanda para a Ilha de Santa Cruz.

Poucos entrevistados

consideraram que o papel das autoridades em manter a ordem e a limpeza dos sítios turísticos é fundamental, por isso também seria importante para as autoridades gerenciarem a construção de rotas alternativas de acesso a todos os setores turísticos de São Cristóvão como, por exemplo, a Praia Ochoa. Os entrevistados (4,2\%) consideraram que devem renovar o serviço de internet fornecido aos turistas na ilha, da mesma forma, é necessário melhorar a atenção e o conforto nos restaurantes e lojas para os turistas.

A chegada de turistas a ilha $(68,85 \%)$ é benéfica economicamente para as grandes empresas, uma vez que traz vantagens, segundo $9,23 \%$ dos informantes, contudo para $13 \%$ dos moradores as atividades turísticas geram pressão ao ecossistema. Porém, não se constituiu como uma ameaça à conservação de Galápagos, de acordo com $88,85 \%$ dos entrevistados, encontrando-se bem gerenciado.

Apesar disso, existe a necessidade de se estabelecer um turismo sustentável nas ilhas. Para tanto, 40\% responderam que é importante fazer o controle dos sítios de visita, 37,31\% opinaram que deve ter um acordo entre as comunidades e as agências de viagem para se estabelecer o ecoturismo nas ilhas; $12,31 \%$ disseram ser necessário o cumprimento das leis que regulam os sítios de visita.

Até 1967 poucos turistas visitaram Galápagos, mas após o sucesso do primeiro cruzeiro realizado em 1967 o número de visitantes aumentou dramaticamente, por exemplo, de 6.000 que visitaram o arquipélago em 1972 a 17. 636 em 1980. Nesta situação, uma comissão de alto nível foi estabelecida no ano de 1981 e um máximo anual de 25.000 turistas por ano foi novamente estabelecido com uma média de seis dias de estadia. Em 1983, a capacidade real de carga dos locais de visita foi calculada com base em fatores como: erosão da trilha em cada local de visita, perturbação da fauna, entre outros. Para o Plano de Manejo do Parque Nacional de Galápagos a capacidade de carga real é de 41.767 turistas por ano (GRENIER, 2007, p.281).

De acordo com Bassett (2009, p.16), a maioria das empresas de turismo em Galápagos contribui pouco com a economia local. O número de turistas cresceu sendo necessário maior 


\section{SISTEMA SÓCIO-ECOLÓGICO DA ILHA SÃO CRISTÓVÃO, GALÁPAGOS: UMA ANÁLISE A PARTIR DAS PERCEPÇÕES DOS ATORES LOCAIS}

número de embarcações. Portanto, o desejo dos entrevistados é ter um turismo mais equitativo com a comunidade. Sob essa ótica, também é basilar que as autoridades promovam mais oportunidade para São Cristovão para que os turistas permaneçam pelo menos um dia desfrutando das suas praias, da gastronomia e do artesanato produzidos na cidade.

Apesar de que na percepção dos moradores de São Cristovão, o turismo não ameaça a conservação da biodiversidade, estudiosos, como Barriga (2015, p.409), afirmam que o turismo é uma atividade a ser praticada, mantendo um equilíbrio entre o meio ambiente $\mathrm{e}$ o desenvolvimento das reservas de biosfera. No caso de Galápagos, o turismo por si é um dos principais fatores de risco para a conservação da biodiversidade, devido ao aumento acelerado do número de turistas (BARRIGA, 2015, p.409; WALSH; MENA, 2016, p.14536).

\subsection{Resíduos Sólidos e Tratamento das Águas residuais}

A respeito dos resíduos sólidos em São Cristóvão, os entrevistados afirmaram que a gestão desses resíduos melhorou pela boa administração das autoridades a partir de 2004 (69\%); $21 \%$ argumentaram que falta informação e conscientização sobre o manejo dos resíduos e $5 \%$ mencionaram a formulação de leis como entraves à gestão municipal. $O$ processo completo de gestão de resíduos sólidos é liderado pela Unidade de Gestão Ambiental do Município responsável pela coleta, transporte e gestão no Centro de Gerenciamento de Resíduos Sólidos e quanto ao seu destino final, os entrevistados têm preocupações sobre o destino dos resíduos, uma vez que estes chegam ao continente.

\section{A UNESCO declarou Galápagos}

Patrimônio Natural da Humanidade e o governo, ao estabelecer seu compromisso com a conservação, cria a Lei Especial de Galápagos em 1998, que estabelece saúde, educação, saneamento, entre outros. A esse respeito, os entrevistados acreditam que seria bom promulgar leis adicionais para atingir um nível máximo em políticas de tratamento de resíduos sólidos. Eles concordaram que a geração de resíduos sólidos é pequena, devido à ausência de fábricas ou indústrias. Além disso, muitos moradores reciclam o lixo inorgânico ou queimam, e o orgânico serve para compostagem. A queima de lixo é feita pelos moradores do Cerro Verde, porque o serviço de coleta dos resíduos pelo município de São Cristóvão não é contínuo.

No que diz respeito ao tratamento de água, $68,85 \%$ dos entrevistados concordaram que existe um sistema eficaz, mas que apresenta inconvenientes, como falhas no sistema causadas por fortes chuvas que colapsam alguns tubos, mau cheiro e, na estação chuvosa, o tubo de encanação de água encontrada na Praia de Oro colapsa e parte desta água vai para o mar, sem manutenção da obra.

$\mathrm{Na}$ gestão de águas residuais, a área urbana tem serviço de tratamento de esgoto, em que há esforços para tratar bem a água. Entretanto, necessita de mais investimento na implementação de um laboratório que realize a análise e o controle permanente da qualidade da água tratada antes de sua disposição final na Baía de Naufrágio.

\subsection{Reconhecimento de Galápapos como Patrimônio de Valor Universal}

Interrogados sobre Galápagos ser declarada como Patrimônio de Valor Universal pela UNESCO, 63,46\% dos entrevistados expressaram um resultado positivo, o que significa que eles concordam que os ecossistemas marinhos e terrestres devem ser conservados para as gerações presentes e futuras. Outros 18,46\% mostraram ignorância em relação ao assunto, tornando evidente a falta de informação, como é o caso dos $18,08 \%$ dos entrevistados que optaram por não responder.

Aproximadamente $49 \%$ dos informantes se sentiram privilegiados em viver nesse ambiente, mas $43 \%$ reconheceram que seja uma responsabilidade de manter o patrimônio natural da humanidade, estando sujeita a diferentes 


\section{SISTEMA SÓCIO-ECOLÓGICO DA ILHA SÃO CRISTÓVÃO, GALÁPAGOS: UMA ANÁLISE A PARTIR DAS PERCEPÇÕES DOS ATORES LOCAIS}

regulamentos para minimizar impactos por atividades humanas.

Os entrevistados sabiam que Galápagos foi declarada Patrimônio do Valor Universal Excepcional pela UNESCO em 2013 e eles concordaram que é um orgulho viver neste Patrimônio. No entanto, existem limitações, como as áreas de pesca, as quais estão inseridas em áreas de conservação. Essas circunstâncias tornam Galápagos um valioso laboratório socioeconômico para pesquisas sobre o desenvolvimento de interações entre sistemas sociais e naturais, bem como uma referência para monitorar as conseqüências das atividades humanas nos ecossistemas e nos processos naturais diante de mudanças globais (GONZÁLEZ et al., 2008, p.13).

\subsection{Pesca}

Na ilha São Cristóvão, segundo 62\% dos entrevistados, ocorre pesca ilegal, especialmente em época de reprodução, inclusive de espécies ameaçadas, a exemplo, do tubarão. As principais ameaças provêm de navios nacionais e estrangeiros, incentivados pelos mercados asiáticos. De acordo com 32\% dos entrevistados, existem muitas restrições e regulamentos, por exemplo, em áreas que anteriormente estavam liberados para a pesca nas ilhas de Darwin e Wolf. Pescadores locais tiveram que se mudar dessas áreas de conservação sem alguma compensação, ficando também sem o oferecimento de alternativas por parte do Estado. Também, 20\% dos informantes apontaram que falta controle pelas autoridades no monitoramento da Reserva Marinha de Galápagos.

Bassett (2009, p.173) afirma que a Reserva Marinha de Galápagos tornou-se a sétima maior reserva do mundo, sendo constituída pelo governo equatoriano, mas gerencialmente impossível de monitorar. Esta situação de fragilidade favorece a pesca excessiva de pepino de mar, a caça de tubarão, e o uso de práticas de pesca proibidas do tipo "palangre". O pepino do mar (Isostichopus fuscus ${ }^{5}$ Ludwig, 1875), em particular, é uma espécie esgotada em Galápagos. Em 1990, as capturas foram iniciadas devido à sua alta demanda no mercado asiático. Em 1995, um grupo de pescadores descontentes lutou com os escritórios do Parque Nacional de Galápagos, porque não concordava com quotas estabelecidas para o pepino do mar, o que gerou discussões entre ambientalistas e pescadores, e um eventual colapso do pepino do mar (NICHOLS, 2014, p.136). No primeiro censo de 2001, em uma área do tamanho de um campo de futebol, 115 espécimes de pepino do mar foram recolhidos na Ilha Fernandina para ser explorada comercialmente. Atualmente na mesma área, existem menos do que cinco amostras, e a baixa densidade tem levado a sua quase extinção (NICHOLS, 2014, p.25). Hoje, o resultado dessa exploração, é que o pepino do mar estava seriamente ameaçado (BASSETT, 2009, p.229). Para esta espécie, $68,46 \%$ dos entrevistados expressaram que está ameaçado, no entanto, $21,15 \%$ dos entrevistados não conhecem o assunto e $10,38 \%$ não responderam.

\subsection{Espécies vegetais introduzidas}

$\mathrm{Na}$ ilha, 47,69\% consideraram que as espécies exóticas são uma ameaça para as espécies endêmicas, já que competem com estas. Também é um problema na agricultura, porque elas invadem as áreas, podendo ser portadores de doenças ou posteriormente tornarem-se pragas. Um dos riscos de introdução de espécies é o aumento nas viagens aéreas de Guayaquil para Galápagos, segundo $63,08 \%$ dos entrevistados, e os navios que transportam carga do porto de Guayaquil para as ilhas, apontados por $83 \%$ dos interlocutores. Conforme indicado

\footnotetext{
${ }^{5}$ Espécie que está catalogada "Em perigo" para a União Internacional para Conservação da Natureza (IUCN), porque verificaram-se importantes reduções populacionais em várias partes do espectro desta espécie. A área de maior densidade conhecida para esta espécie, as Ilhas Galápagos, teve reduções na ordem de $80 \%$ ou mais.
} 


\section{SISTEMA SÓCIO-ECOLÓGICO DA ILHA SÃO CRISTÓVÃO, GALÁPAGOS: UMA ANÁLISE A PARTIR DAS PERCEPÇÕES DOS ATORES LOCAIS}

por $81 \%$ dos moradores, estas espécies são ameaça à flora e fauna endêmica da ilha.

A espécie vegetal Rubus niveus Thunb., que é uma planta agressiva, de acordo com informação de $13,46 \%$, proliferou devido ao abandono da terra. As extensas plantações de amora são consideradas ameaças à vegetação endêmica e nativa, localizadas nas áreas agrícolas da Ilha de São Cristóvão e podem ser vistas em todos os lugares. Rubus niveus é uma espécie que foi introduzida para fins agrícolas em São Cristóvão nos anos 1975 e 1978 (RENTERIA, et al., 2012, p.2). A Fundação Charles Darwin relatou que é uma das piores plantas invasoras, penetra todos os tipos de solo, ocupa espaços na vegetação nativa e uma vez estabelecida pode formar moitas densas impenetráveis e espinhoso, competindo com vegetação nativa e plantas endémicas (CABI, 2018 p.1). A introdução de espécies exóticas em Galápagos é uma das ameaças mais graves para a conservação de espécies nativas que está indiretamente associada ao aumento do número de turistas e residentes para as ilhas (BARRIGA, 2015, p.409).

A maioria das pessoas (75\%) conhece as medidas de biossegurança, entre as quais, a mais apropriada é a que oferece maior informação aos turistas para conservar a biodiversidade. Neste caso, $66 \%$ dos informantes consideraram que a medida funciona corretamente. Entretanto, $51,5 \%$ sugeriram que, a implantação do cais na ilha de Baltra e na cidade de Guayaquil, iria favorecer os controles, e 41,54\% sugeriram que aumentaria os custos do transporte de mercadorias, o que elevaria o custo de vida.

De acordo com 73\% dos entrevistados, é possível alcançar uma agricultura local sustentável (baixo impacto nas ilhas) e, assim, reduzir a renda dos produtos do Equador, isso diminuiria a entrada de espécies introduzidas nas ilhas.

\subsection{Ordenamento institucional}

Os moradores locais podem ocupar cargos públicos na região e como estratégias para isso, os entrevistados responderam que é imprescindível que haja preferência pelos residentes para ocupar os cargos; que existam universidades públicas no estado e formação de microempresas. A opinião de $41,31 \%$ é de que as vagas de emprego deveriam ser ocupadas primeiro pelos moradores, mas $46,92 \%$ dos entrevistados sugeriram que os residentes deveriam ter estudos universitários e se especializar em diferentes áreas do conhecimento, conhecer outras línguas, entre outras habilidades que facilitariam a competitividade das pessoas provenientes do Equador continental. Os programas de treinamento, segundo 30,08\% dos entrevistados são necessários para microempresas, ou seja, na instalação e gerenciamento de uma empresa.

É comum encontrar pessoas do continente equatoriano trabalhando em cargos públicos como funcionários, assessores em instituições como o Conselho de Governo, o Parque Nacional de Galápagos e na área de Saúde, em que esta situação foi permitida pela Lei Especial de Galápagos ao estabelecer o termo "Preferente".

$\mathrm{O}$ residente para escolher um emprego deve participar de competições públicas, mas o que define no final, o trabalho ou não, são as habilidades adquiridas como estudos de pósgraduação, línguas, experiência e estar ligados na política, entre outros. Esta é uma séria desvantagem para os residentes, porque as pessoas que residem no continente equatoriano têm uma melhor chance de treinar, aprender línguas, ter uma melhor experiência e participar ativamente da política, enquanto que o residente de São Cristóvão não tem a mesma oportunidade.

A grande maioria dos entrevistados, representada por $83,85 \%$, está ciente da lei especial de Galápagos, e $18,46 \%$ das entrevistadas sabiam que a mesma foi criada como estratégia de conservação. Os entrevistados concordaram que esta Lei orienta Galápagos para a conservação de sua biodiversidade. Contudo, restringe a pesca artesanal somente aos que tem licença, e os agricultores não podem contratar pessoas do continente para trabalhar porque este 
ANDRADE, L. V. M., LOBATO, G. J. M. , TOLEDO, P. M. , VIERIA, I. C. G.

\section{SISTEMA SÓCIO-ECOLÓGICO DA ILHA SÃO CRISTÓVÃO, GALÁPAGOS: UMA ANÁLISE A PARTIR DAS PERCEPÇÕES DOS ATORES LOCAIS}

procedimento é muito burocrático, os custos são altos, devem ser adicionadas as seguintes taxas: Seguro de fazendeiro + Seguro Instituto Equatoriano de Segurança Social + garantia ao Conselho de Governo + salário. Nesse sentido, isso torna difícil para o agricultor trazer trabalhadores do Equador continental.

A respeito do Parque Nacional de Galápagos 46,92\% dos entrevistados acreditam que o mesmo contribui para a conservação da biodiversidade, e $75 \%$ sugeriram que o zoneamento é importante para o gerenciamento da área protegida, mas deve ser analisado bem, porque um setor pode ser prejudicado e beneficiar outros setores, como o turismo e a pesca.

\subsection{Análise estatística dos condutores de mudanças}

As informações obtidas sobre os condutores de mudanças na Ilha São Cristovão foram tratadas estatisticamente a fim de entender a complexidade das relações entre gestão de conservação biológica e os aspectos administrativos, bem como, os padrões das respostas diante dos principais alinhamentos da dinâmica institucional que atua sobre as regras administrativas em Galápagos.

As variáveis foram dispostas em grupos, os quais elucidam as relações de associação ou de oposição que estabelecem entre si. A primeira dimensão ou Fator 1 (F1) apresentou um grau de generalidade bastante satisfatório uma vez que 34 modalidades, de um total de 60, tiveram registros de coordenadas com correlações maiores, e para o Fator 2 (F2) foi encontrado 26 modalidades (Tabela 2). O que diferencia uma modalidade da outra, quando estão correlacionadas no mesmo fator, na maioria das vezes, é a coordenada positiva ou negativa. Assim, as duas dimensões são formadas pelas associações das principais ameaças: turismo, resíduos sólidos e tratamento de água residual, reconhecimento de Galápagos como Patrimônio Universal, pesca, espécies introduzidas e ordenamento institucional.

Tabela 2 - Distribuição das variáveis nos grupos. Legenda: As marcações em verde são referentes à variável de maior representatividade de cada grupo.

\begin{tabular}{c|c|c|c}
\hline Grupo 1 & Grupo 2 & Grupo 3 & Grupo 4 \\
\hline Factor 1 - & Factor 1 + & Factor 2 - & Factor 2 + \\
\hline$A 1: 0$ & $A 1: 1$ & $A 3: 0$ & $A 3: 1$ \\
\hline$A 2: 0$ & $A 2: 1$ & $A 5: 0$ & $A 5: 1$ \\
\hline$A 4: 0$ & $A 4: 1$ & $A 6: 0$ & $A 6: 1$ \\
\hline$A 12: 0$ & $A 12: 1$ & $A 7: 0$ & $A 7: 1$ \\
\hline$A 13: 0$ & $A 13: 1$ & $A 8: 0$ & $A 8: 1$ \\
\hline$A 15: 0$ & $A 15: 1$ & $A 9: 0$ & $A 9: 1$ \\
\hline$A 16: 0$ & $A 16: 1$ & $A 10: 0$ & $A 10: 1$ \\
\hline$A 17: 0$ & $A 17: 1$ & $A 14: 0$ & $A 11: 1$ \\
\hline$A 18: 0$ & $A 18: 1$ & $A 19: 0$ & $A 14: 1$ \\
\hline$A 20: 0$ & $A 20: 1$ & $A 22: 0$ & $A 19: 1$ \\
\hline$A 21: 0$ & $A 21: 1$ & $A 25: 0$ & $A 22: 1$ \\
\hline$A 23: 0$ & $A 23: 1$ & $A 29: 0$ & $A 25: 1$ \\
\hline$A 24: 0$ & $A 24: 1$ & & $A 29: 1$ \\
\hline$A 26: 0$ & $A 26: 1$ & & \\
\hline$A 27: 0$ & $A 28: 1$ & & \\
\hline$A 28: 0$ & $A 30: 1$ & & \\
\hline$A 30: 0$ & & & \\
\hline
\end{tabular}


ANDRADE, L. V. M., LOBATO, G. J. M. , TOLEDO, P. M. , VIERIA, I. C. G.

\section{SISTEMA SÓCIO-ECOLÓGICO DA ILHA SÃO CRISTÓVÃO, GALÁPAGOS: UMA ANÁLISE A PARTIR DAS PERCEPÇÕES DOS ATORES LOCAIS}

Cada grupo apresentou variáveis mais relevantes, assim foi possível identificar que "A20: 0 O sistema de biossegurança não está funcionando corretamente" (Grupo 1 Fator 1-); "A28:1 É possível alcançar uma agricultura local sustentável de baixo impacto na ilha São Cristóvão" (Grupo 1 Fator 1 +); "A19:0 Aumento de chegadas de embarcações de carga a ilha São Cristóvão não aumenta o risco de ingresso de espécies introduzidas" (Grupo 3 Fator 2 -) ,e "A6:1 Tem melhorado a administração do sistema de resíduos sólidos" (Grupo 4 Fator 2 +) (Tabela 2). Corroborando com esses dados, a figura 5 apresenta essas variáveis no plano fatorial 1 e 2 , em que é possível identificar grupos de residentes com diferentes percepções de ameaças.

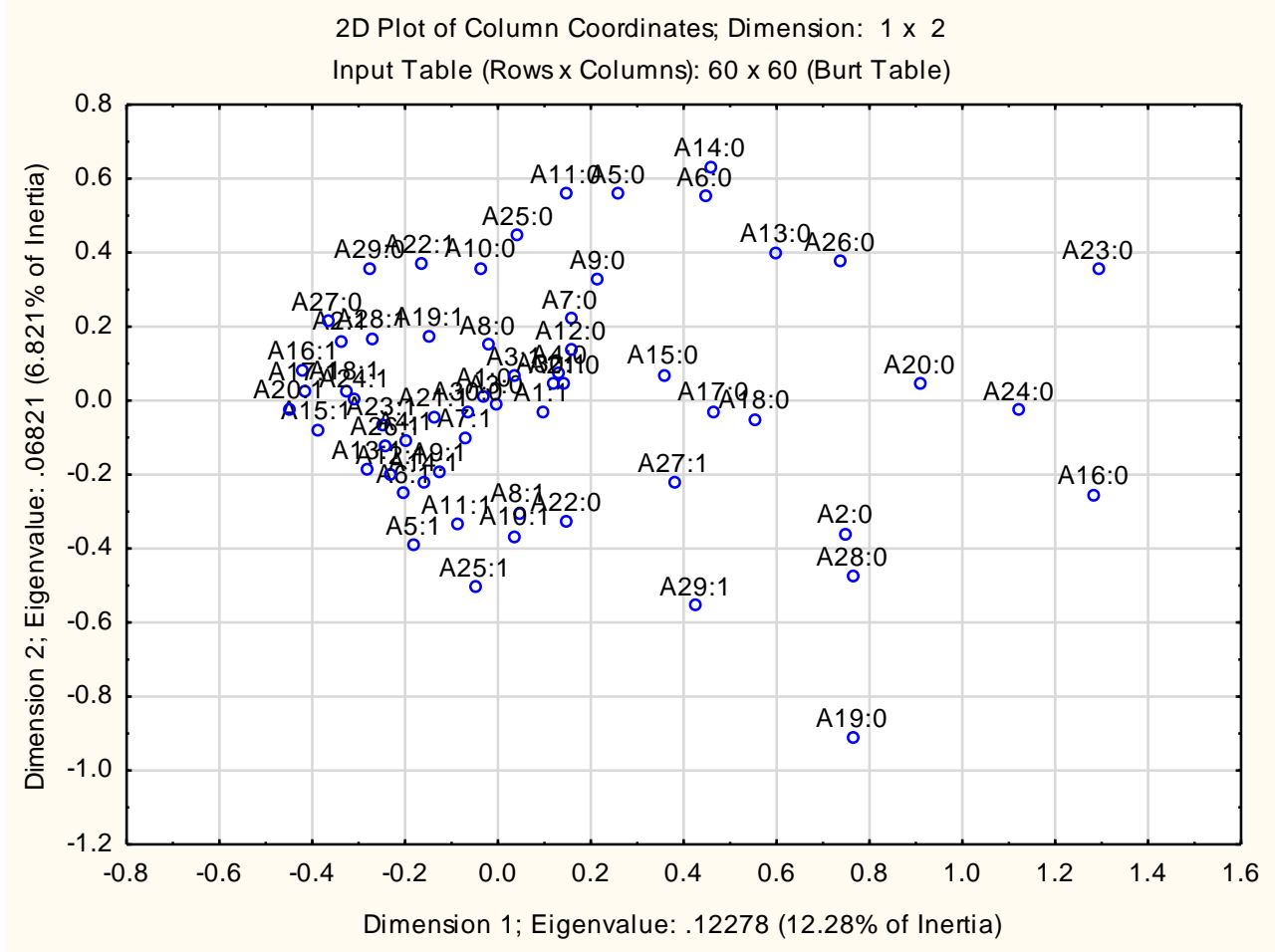

Figura 5 - Localização das variáveis no plano Fatorial 1 e Fatorial 2.

Na figura 6, é possível observar grupos claramente formados. Ao lado esquerdo da figura 6 há um grupo uniforme com 22 variáveis e no direito um grupo mais disperso composto por oito variáveis. Para este último observa-se que aparecem questões relacionadas ao turismo (A1: 1; A3: 1 e A4: 1), aos resíduos sólidos (A8: 1), ao patrimônio natural (A10: 1), a gestão do Parque Nacional (A25: 1 ), as espécies introduzidas (A29: 1) e a mina (A30: 1). Neste caso, é importante ressaltar que existe uma tendência a respostas positivas, sugerindo alguns impactos no modo de vida local a exemplo do turismo, das espécies introduzidas e da mina. 
ANDRADE, L. V. M., LOBATO, G. J. M. , TOLEDO, P. M. , VIERIA, I. C. G.

\section{SISTEMA SÓCIO-ECOLÓGICO DA ILHA SÃO CRISTÓVÃO, GALÁPAGOS: UMA ANÁLISE A PARTIR DAS PERCEPÇÕES DOS ATORES LOCAIS}

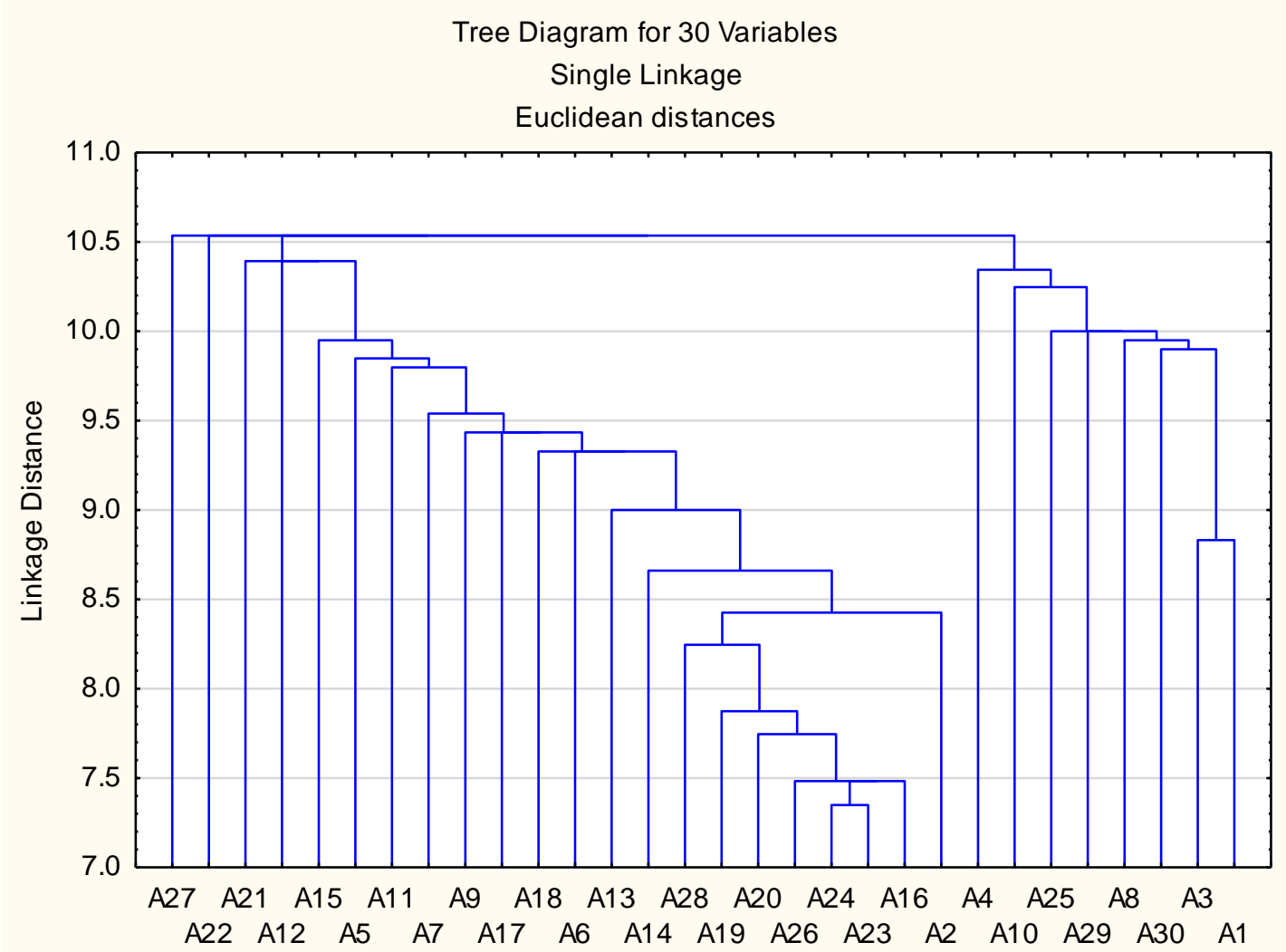

Figura 6.- Dendograma de saída de análise de agrupamento para um grupo de 260 residentes da Ilha São Cristóvão.

\section{CONSIDERAÇÕES FINAIS}

Diante de uma situação de gestão e controle territorial do arquipélago, a dinâmica do SSE foi analisada pela perspectiva do componente social. Neste sentido, as percepções dos atores locais permitiram concluir que existe uma convivência prazerosa nas cidades e povoados, onde existe tranquilidade, segurança e a disponibilidade do espaço natural como um ambiente lúdico. Contudo, diante de certos problemas ambientais, como a falta de água potável e restrições de uso de alguns recursos (pesca), a interação sociedade e ambiente se dá numa dinâmica que necessita de averiguação e controle por orgãos oficiais. Principalmente nos aspectos do aumento do turismo, espécies introduzidas, pesca ilegal, migração e geração de resíduos sólidos.

Para entender a llha de São Cristóvão, é necessário descrever que falta mão-de-obra, existem altos custos de insumos agrícolas e transporte de produtos das fazendas para a comunidade. E para o seu comércio é complicado, não há projetos da coleta de águas subterrâneas, falta um sistema de irrigação, deixando as culturas dependentes da chuva, falta trabalho local, ou seja, é difícil obter moradores que desejam trabalhar, e ao procurar pessoas do continente aumentam a população e a migração.

Recomenda-se que as autoridades promovam mais oportunidade para a llha São Cristóvão para que os turistas permaneçam pelo menos um dia desfrutando das suas praias, da gastronomia e do artesanato produzidos na cidade, pois os entrevistados não visualizam o turismo como ameaça desde que traga benefícios a todos. Faz-se necessário também fortalecer a Agência de Biossegurança, investindo recursos financeiros para contratação de mais técnicos, adquirindo tecnologia como os raios "X", solicitando um porto de quarentena para uma revisão abrangente de cada navio estrangeiro ou nacional que chega à ilha e implantando piscinas 


\section{SISTEMA SÓCIO-ECOLÓGICO DA ILHA SÃO CRISTÓVÃO, GALÁPAGOS: UMA ANÁLISE A PARTIR DAS PERCEPÇÕES DOS ATORES LOCAIS}

de água doce e raios ultravioleta, as quais tendem a eliminar todas as incrustações que têm no casco dos barcos.

O SSE de Galápagos, a partir das percepções dos moradores, necessita de mudanças para melhorar sua capacidade adaptativa frente às perturbações que têm experimentado. Os condutores de mudança: turismo, resíduos sólidos e tratamento de água residual, reconhecimento de Galápagos como Patrimônio, pesca, espécies introduzidas e ordenamento institucional demonstraram um sistema complexo que requer transformações nas suas estruturas para elevar a qualidade de vida da população residente e para que tenha conservado a biodiversidade local, de modo que seja possível seu uso por gerações futuras.

\section{REFERÊNCIAS}

ATHAYDE, S.; BERNASCONI, P.; BARTELS, W.L.; SELUCHINESK, R.; BUSCHBACHER, R. Avaliação da resiliência socioecológica como ferramenta para a gestão da fronteira amazônica: experiências e reflexões. Sustentabilidade em Debate, Brasília, v.7, n.2, p.14-19, 2016.

BARRIGA, A.M. La contradicción del turismo en la conservación y el desarrollo en GalápagosEcuador. Estudios y perspectivas en turismo, Ciudad Autónoma de Buenos Aires, v.24, n.2, p.399-413, 2015.

BASSETT, C.A. Galapagos at the Crossroards: pirates, biologits, tourists, and creationists battle for Darwin's cradle of evolution. Washington DC: National Geographic Books, 2009.

BUSCHBACHER, R. A Teoria da resiliência e os sistemas socioecológicos: como se preparar para um futuro imprevisível?. Boletim regional, urbano e ambiental, n.9, p. 11-24, 2014.

BUSCHBACHER, R.; ATHAYDE, S.; BARTELS, W.L.; MELLO, R. Resilience Assessment as a tool for understanding the Amazon frontier as a socialecological system. Sustentabilidade em Debate, Brasília, v.7, n.2, p.20-35, 2016.
CABI. Invasive Species Compendium. Disponível em:

<https://www.cabi.org/isc/datasheet/107939>2. 2018. Acesso em: 01 set. 2018.

CAIRNS, R. A critical analysis of the discourses of conservation and science on the Galápagos Islands. University of Leeds: Disponível em: Http://etheses.whiterose.ac.uk/2301/1/Cairns_R _PhD_2011.pdf, 2011. 241 p. >. Acesso em: 01 set. 2018.

DPNG, Dirección del Parque Nacional Galápagos. Plan de Manejo Parque Nacional Galápagos. 2005. Puerto Ayora, Galápagos, Ecuador. Disponível em: https://pt.scribd.com/document/333817633/DP NG-Plan-de-Manejo-Parque-Nacional. Acesso em: 08 out. 2016.

DPNG, Dirección del Parque Nacional Galápagos. Plan de Manejo de las Áreas Protegidas de Galápagos para el Buen Vivir. 2014. Puerto Ayora, Galápagos, Ecuador. Disponível em: http://www.galapagos.gob.ec/wpcontent/uploads/downloads/2016/07/DPNG_PI an_de_Manejo_2014.pdf. Acesso em: 01 out. 2016.

ECHEVERRIA, H.; QUIROGA, D.; TORAL GRANDA, $V$. Manual de aplicación del derecho penal ambiental como instrumento de protección de las áreas naturales de Galápagos. Sea Shepherd, World Wildlife Fund y Galalpagos Academic Institute for the Arts and Sciences de la Universidad San Francisco de Quito- Ecuador, 2011.

GALAPAGOS. Ley de Especial de Galápagos publicado el 18 de marzo de 1998. QuitoEcuador. $\mathrm{n}$ 67, p.32, 1998. Disponível em http://www.ambiente.gob.ec/wpcontent/uploads/downloads/2015/02/LEYORGANICA-DE-REGIMEN-ESPECIAL-PARA-LAPROVINCIA-DE-GALAPAGOS.pdf>.Acesso em: 01 out. 2016.

GONZÁLEZ, J.; MONTES, C.; RODRÍGUEZ, J.; TAPIA, W. Rethinking the Galapagos Islands as a complex social-ecological system: implications for 


\section{SISTEMA SÓCIO-ECOLÓGICO DA ILHA SÃO CRISTÓVÃO, GALÁPAGOS: UMA ANÁLISE A PARTIR DAS PERCEPÇÕES DOS ATORES LOCAIS}

conservation and management. Ecology and Society, Nova Scotia, v.13, n.2, p.13-26, 2008.

GRANT, P.; GRANT, R. How and way species multiply. The radiation os darwin finches. Princepton University Press. 2008.

GRENIER, C. Conservacion contra natura: Las islas Galapagos. QUITO ECUADOR: ABYA-YALA, 2007. $463 \mathrm{p}$.

GROOT, R.S. Evaluation of enviromental functions as a tool in planning, management and decision-making. Wolters-Noordhoff: [s.n.], 1992. 315 p.

IDROVO, H. Galapagos footsteps in the paradise: Crucible. 1 edição. Galápagos: Libreria Ediciones Quito’Equador-Libri Mundi, 205p. 2005.

IUCN. União Internacional para Conservação da Natureza. Disponível em: http://www.iucnredlist.org/details/180373/0. Acesso em: 01 set. 2018.

LARSON, E.J. Evolution's Workshop: God and Science on the Islands. [S.I.]. London 2002.

NICHOLLS, $\mathrm{H}$. The galapagos a natural history. New York: [s.n.], 2014. 144 p.

PALOMO, I.; MONTES, C.; MARTÍN-LÓPEZ, B.; GONZÁLEZ, J. A.; GARCÍA-LLORENTE, M.; ALCORLO, P.; MORA, M. R. G. Incorporating the social-ecological approach in protected areas in the Anthropocene. BioScience, Oxford, v.64, n.3, p.181-191, 2014.

RENTERIA, J.; GERDENER, M.; PENETTA, D. Possible Impacts of the Invasive Plant Rubus niveus on the Native Vegetation of the Scalesia Forest in the Galapagos Islands. PLOS ONE, [S.L], v.7, n.10, p.1-8, 2012. Disponível em: <https://journals.plos.org/plosone/article/file?id $=10.1371 /$ journal. pone.0048106>. Acesso em: 01 set. 2018.

SANTOS, G.L.; HAUFF, S.N.; MOTTA, C.L.; LOYOLLA, I.N.; BARBOSA, J.P.; PEQUENO, M. C.; CAMPOS, H.L. Pelos Caminhos de Darwin: um material multimidiático interativo de divulgação científica. Nuevas Ideas en Informática
Educativa, Porto Alegre, v.55, n.61, p. 249-260, 2015.

SCATENA, L.M. Ações em educação ambiental: análise multivariada da percepção ambiental de diferentes grupos sociais como instrumentos de apoio à gestão de pequenas bacias - estudo de caso da microbacia do córrego da Capituva, Macedônia, SP. 2005. 262f. Tese (Doutorado em Hidráulica e Saneamento) - Escola de Engenharia de São Carlos, São Carlos.

SECRETARIA NACIONAL DE PLANEJAMENTO. Proyecciones referenciales de población a nivel de cantonal - Parroquial periodo 2010-2020. Disponível em: http://sni.gob.ec/ proyecciones-yestudios-demograficos). Acesso em: 20 mar. 2017.

SOBREIRO, T. Dinâmica Socioecológica e Resiliência da Pesca Ornamental no Rio Negro, Amazonas, Brasil. Sustentabilidade em Debate, Brasília, v. 7, n. 2, p. 118-134, 2016.

TAPIA, W.; GONZÁLEZ NOVOA, J.A.; OSPINA, P.; QUIROGA, D.; RECK, G.; MONTES DEL OLMO, C. Entendiendo Galápagos como un sistema socioecológico complejo: implicaciones para la investigación científica en el archipiélago. 2009. Disponível em: https://repositorio.uam.es/bitstream/handle/104 86/3210/23094_cap_tapia.pdf?sequence=1.

Acesso em: 01 jan. 2017.

THEOFILOS, T. Volcanica Galápagos Volcanico. Ediecuatorial. Quito. 2011.

UNESCO. Organização das Nações Unidas para Educação, Ciência e Cultura. Intergovernmental Committee for the protection of the world cultural and natural heritage. Galapagos ecosystem in a state of risk and national priority his conservation. Then UNESCO Decides to inscribe the Galapagos Islands (Ecuador) in the List of World Heritage in Danger. 2007. Disponível em:

<http://whc.unesco.org/en/list/1/documents/>. Acesso em: 01 out. 2016. 
ANDRADE, L. V. M., LOBATO, G. J. M. , TOLEDO, P. M. , VIERIA, I. C. G.

SISTEMA SÓCIO-ECOLÓGICO DA ILHA SÃO CRISTÓVÃO, GALÁPAGOS: UMA ANÁLISE A PARTIR DAS PERCEPÇÕES DOS ATORES LOCAIS

WALSH, S.J.; MENA, C.F. Interactions of social, terrestrial, and marine sub-systems in the Galapagos Islands, Ecuador. Proceedings of the National Academy of Sciences, United States of America, v.113, n. 51, p. 14536-14543, 2016.

WALLACE, A.R. On the law which has regulated the introduction of new species. Scientiae Studia, São Paulo, v. 1, n. 4, p. 531-548, 2003.

WATKINGS, G.; MARTINEZ, A. The changing organizational framework in Galapagos. GALAPAGOS REPORT 2007 - 2008, Santa Cruz, p. 60-68, mar./abr., 2007. Disponível em: https://www.galapagos.org/wpcontent/uploads/2012/01/changing-orgframework-watkinsmartinez.pdf >Acesso em: 01 set. 2018. 